\title{
Composition of the Lipopolysaccharide from Different Capsular Serotype Strains of Haemophilus influenzae
}

\author{
By SUSANNE E. ZAMZE* $†$ AND E. RICHARD MOXON \\ Infectious Diseases Unit, Department of Paediatrics, John Radcliffe Hospital, Headington, \\ Oxford $O X 39 D U, U K$
}

(Received 10 September 1986; revised 4 December 1986)

\begin{abstract}
Lipopolysaccharide (LPS) from all six serotype strains of Haemophilus influenzae was similar in composition. The oligosaccharide, of each LPS, was composed of glucose, galactose, heptose and 2-keto-3-deoxyoctonic acid. The lipid A was composed of glucosamine, phosphate and the fatty acids 14:0 and 3-OH 14:0. Each LPS also contained ethanolamine and ethanolamine phosphate, and the oligosaccharides from two strains additionally contained small amounts of glucosamine. Although the LPS was similar in composition, different serotypes had quantitative differences, especially in the galactose content, which correlated with the antigenic specificity of their homologous antisera and with their mobility on SDS-polyacrylamide gel electrophoresis (SDS-PAGE). A survey by SDS-PAGE showed that LPS from strains of the serotypes a, $c$ and $d$ was characteristically of lower $M_{\mathrm{r}}$ than the LPS from most $(80 \%)$ serotype b strains.
\end{abstract}

\section{INTRODUCTION}

Haemophilus influenzae is widespread in the human population, where it colonizes the nasopharynx. Although normally commensal, it has the potential to cause systemic infection in children, including meningitis. It is either non-capsular or expresses one of six antigenically and chemically distinct capsular polysaccharides, designated types a-f (Pittman, 1931). The majority of strains causing systemic infection synthesize the type b capsule, an acidic polysaccharide with the repeating unit of ribosyl-ribitol-phosphate (PRP) (Moxon \& Vaughn, 1981; Turk, 1982). Although the type b capsule is known to be a major virulence factor, a potential role for non-capsular surface components such as the lipopolysaccharide (LPS) of this organism has been indicated by the results of recent studies. These have shown an association between virulence and alterations in LPS as a result of transformation (Zwahlen et al., 1983, 1985 ) and also an apparent relationship between virulence and the presence of certain antigenic determinants in $H$. influenzae type b LPS as defined by monoclonal antibodies (Kimura \& Hansen, 1986).

$H$. influenzae LPS also displays endotoxic properties similar to those of enterobacterial LPS (Flesher \& Insel, 1978) and may be involved in the acquisition of serum resistance (Inzana \& Anderson, 1985). Previous studies have shown the LPS to possess a lipid A moiety and an oligosaccharide, but to lack a high- $M_{\mathrm{r}}$ sidechain polysaccharide (Flesher \& Insel, 1978; Inzana, 1983). Because of the apparent rough nature of this LPS the term lipo-oligosaccharide is currently being employed by a few authors. However, we prefer to retain the original terminology in order to specify a molecule which has the biological and structural characteristics of an LPS.

† Present address: Oxford Oligosaccharide Group, Department of Biochemistry, Oxford University, South Parks Road, Oxford OX1 3QU, UK.

Abbreviations: LPS, lipopolysaccharide; KDO, 2-keto-3-deoxyoctonic acid; PCP, phenol/chloroform/light petroleum; TBA, thiobarbituric acid. 
A chemical analysis of the oligosaccharide from the LPS of a virulent type b strain revealed similarities to, but also some differences from, the composition of the core region of enterobacterial LPS (Inzana et al., 1985). However, other than two brief reports (Flesher \& Insel, 1978; Parr \& Bryan, 1984), no information regarding the structure of LPS from serotypes other than $b$ is available. In order to assess the extent of possible chemical variation of $H$. influenzae LPS, a more detailed analysis of the LPS from the different capsular serotypes of $H$. influenzae was felt to be warranted.

In this paper we report the chemical and immunochemical analysis of the LPS from one representative strain of each capsular serotype, $\mathrm{a}-\mathrm{f}$, and a survey by SDS-PAGE of LPS from different capsular isolates.

\section{METHODS}

Bacteria. LPS from the following strains was analysed chemically: Morgan (type a); Eagan (type b); ATCC 9007 (type c); ATCC 9008 (type d); one type e and one type f strain, both from our own collection. The strains are referred to as strains a-f. Bacteria were grown in brain heart infusion broth (BHI; Oxoid) supplemented with haemin (Sigma) $\left(2 \mu \mathrm{g} \mathrm{ml}^{-1}\right)$ and NAD (Sigma) $\left(2 \mu \mathrm{g} \mathrm{ml}^{-1}\right)$ and maintained at $-70^{\circ} \mathrm{C}$ in the same medium containing $20 \%(\mathrm{v} / \mathrm{v})$ glycerol.

Cultivation of bacteria and extraction of LPS. Bacteria were grown at $37^{\circ} \mathrm{C}$ with shaking in $800 \mathrm{ml}$ supplemented BHI broth in 2-litre Erlenmeyer flasks (inoculum, $1 \mathrm{ml}$ of exponential-phase culture). Cells were harvested after $16 \mathrm{~h}$ (at stationary phase) and washed twice with phosphate buffered saline (PBS) (0.15 M-sodium chloride, $0.015 \mathrm{M}$-sodium phosphate, $\mathrm{pH}$ 7.2). LPS was extracted from the cell paste obtained from 51 culture either with hot aqueous phenol (Westphal \& Jann, 1965) or with phenol/chloroform/light petroleum b.p. $40-60^{\circ} \mathrm{C}$ (PCP) according to the procedure of Galanos et al. (1969) modified as previously described (Zamze et al., 1985). PCP extraction was carried out either on lyophilized whole cells or on the lyophilized cell material after phenol/water extraction. LPS, obtained with PCP, was extracted three times with chloroform followed by three extractions with chloroform/methanol $(2: 1, \mathrm{v} / \mathrm{v})$, which removed most extraneous lipid material.

LPS was purified by repeated centrifugation at $100000 \mathrm{~g}$ for $2.5 \mathrm{~h}$ after successive treatment with ribonuclease $\left(0.1 \mathrm{mg} \mathrm{ml}^{-1}\right)$ for $16 \mathrm{~h}$ at $4{ }^{\circ} \mathrm{C}$ and with Pronase $\left(0.125 \mathrm{mg} \mathrm{ml}^{-1}\right)$ for $2 \mathrm{~h}$ at $37^{\circ} \mathrm{C}$ and $\mathrm{pH} 7.4$. LPS was stored in distilled water at $4^{\circ} \mathrm{C}$ over chloroform.

Rapid LPS extracts. Samples of LPS for analysis by SDS-PAGE were extracted on a small scale with phenol/water as described by Inzana (1983). Bacteria were grown in $20 \mathrm{ml}$ supplemented BHI broth at $37^{\circ} \mathrm{C}$ with shaking to late exponential phase (4-5 h growth). Final extracts were dissolved in $300 \mu \mathrm{l}$ distilled water and 20-60 $\mu$ samples applied to the gels.

Chemical methods. Protein content was determined by the Lowry method using bovine serum albumin as the standard. The presence of nucleic acid was monitored by measuring absorbance at $260 \mathrm{~nm}$.

The polysaccharide moiety was completely liberated as monosaccharide and the lipid A precipitated by hydrolysis of the LPS $(2 \mathrm{mg})$ with $2 \mathrm{M}-\mathrm{HCl}$ at $100^{\circ} \mathrm{C}$ for $20 \mathrm{~min}$. Lipid A content was determined gravimetrically as described previously (Smith et al., 1985). Glucosamine in lipid A was liberated by hydrolysis of intact LPS ( $2 \mathrm{mg}$ ) or isolated lipid A (1 mg) with $6 \cdot 1 \mathrm{M}-\mathrm{HCl}$ at $105^{\circ} \mathrm{C}$ for $4 \mathrm{~h}$ under $\mathrm{N}_{2}$.

Sugars were analysed by gas chromatography (GC) as their alditol acetate derivatives. Inositol hexaacetate $(0.1 \mathrm{mg})$ was added as an internal standard and correction factors used for quantification were obtained from authentic standards hydrolysed and derived under identical conditions to LPS. Glucose, heptose and amino sugar content were also determined by colorimetric assays as previously described (Smith et al., 1985) and galactose was also estimated by using galactose dehydrogenase (lactose/galactose, UV-method 17 6303; Boehringer Mannheim). 2-Keto-3-deoxyoctonic acid (KDO) was estimated with thiobarbituric acid (TBA) (Osborn, 1963) either after the hydrolysis of LPS with $4 \mathrm{M}-\mathrm{HCl}$ at $100^{\circ} \mathrm{C}$ for $20 \mathrm{~min}$ (Brade et al., 1983; Parr \& Bryan, 1984) or after treatment of $2 \mathrm{M}-\mathrm{HCl}$ hydrolysates with alkaline phosphatase (Neal \& Wilkinson, 1982). Phosphate was measured by the method of Murphy \& Riley (1962).

Fatty acids were analysed by GC as their methyl esters prepared by the transesterification of LPS or isolated lipid A with $1 \mathrm{M}-\mathrm{H}_{2} \mathrm{SO}_{4}$ in dry methanol at $70^{\circ} \mathrm{C}$ for $8 \mathrm{~h}$ (Salkinoja-Salonen \& Boeck, 1978). Fatty acid methyl esters were identified by co-chromatography with authentic standards. Fatty acids in the LPS of strain b were quantified using methyl octadecanoate $(0.1 \mathrm{mg})$ as an internal standard.

SDS-PAGE. This was done according to the method of Laemmli (1970) using gels of dimensions $18 \times 12 \mathrm{~cm}$. The separating gel had a final concentration of $15 \%(\mathrm{w} / \mathrm{v})$ acrylamide, $0.15 \%$ SDS and $4 \mathrm{M}$-urea. The LPS was mixed with an equal volume of $0.1 \mathrm{M}$-Tris/ $\mathrm{HCl}$ buffer (pH 6.8$)$ containing $4 \%(\mathrm{w} / \mathrm{v}) \mathrm{SDS}, 10 \%(\mathrm{v} / \mathrm{v})$ glycerol, $2 \%$ (v/v) 2-mercaptoethanol and bromophenol blue. Electrophoresis was done at constant current ( $30 \mathrm{~mA} \mathrm{per} \mathrm{gel)}$ until the dye had migrated to the bottom of the gel. LPSs were visualized by the silver stain method of Tsai \& Frasch (1982). 
Immunochemical methods. Antisera were raised against purified LPSs in New Zealand White rabbits. LPSs were

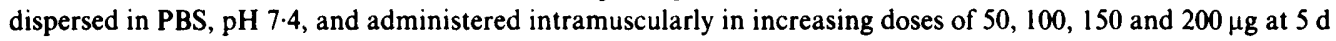
intervals. Blood was collected two to three weeks after the last injection. ELISA was done essentially as described by Thornley et al. (1983) except that the polystyrene microtitre plates (Nunc-Immuno Plate II) were coated by filling the wells of the plate with $50 \mu \mathrm{LPS}\left(5 \mu \mathrm{g} \mathrm{ml} \mathrm{l}^{-1}\right)$ in $0 \cdot 1 \mathrm{M}-\mathrm{Na}_{2} \mathrm{CO}_{3}$ buffer, $\mathrm{pH} \mathrm{9.6}$, and incubating for $18 \mathrm{~h}$ at $4{ }^{\circ} \mathrm{C}$. Bound antibodies were detected with a peroxidase-conjugated anti-mouse immunoglobulin serum (Dako). $o$-Phenylenediamine (OPD) was used as the substrate for the enzyme and absorbance was measured at $492 \mathrm{~nm}$.

Chromatography. Amino components were separated by descending paper chromatography on Whatman no. 1 paper using solvent systems $A$ (pyridine/butan-1-ol/water, $4: 6: 3$, by vol.), B (ethanol/acetic acid/water, $80: 1: 19$, by vol.) and $C$ (butan-1-ol/acetic acid/water, $3: 1: 1$, by vol.).

Solvent system B separated glucosamine, galactosamine and glucosamine-6-phosphate from ethanolamine and ethanolamine phosphate. Components were detected using ninhydrin (Dawson et al., 1969).

Gel permeation chromatography was done using either Sephadex G-50 or G-25 (medium grades, $30 \times 1.5 \mathrm{~cm}$

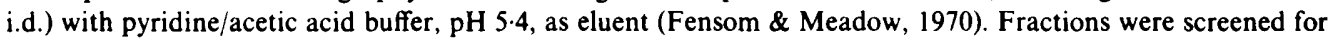
carbohydrate by the phenol/ $\mathrm{H}_{2} \mathrm{SO}_{4}$ method (Dubois et al., 1956).

GC was done with a Pye Unicam 204 gas chromatograph equipped with a flame ionization detector. Fatty acid methyl esters were analysed on two columns: either a packed column ( $3 \mathrm{~m} \times 2 \mathrm{~mm}$ i.d.) of $3 \% \mathrm{SP}-2100 \mathrm{DOH}$ on $100 / 120$ Supelcoport with temperature programming from $150^{\circ} \mathrm{C}$ to $225^{\circ} \mathrm{C}$ at $4{ }^{\circ} \mathrm{C} \mathrm{min}-1$ and $\mathrm{N}_{2}\left(20 \mathrm{ml} \mathrm{min}^{-1}\right)$ as the carrier gas, or a WCOT flexsil quartz capillary column $(30 \mathrm{~m} \times 0.32 \mathrm{~mm}$ i.d.) with a $0.25 \mu \mathrm{m}$ film of $3 \%$ SP2100 and using a $50: 1$ split ratio with temperature programming of $5 \mathrm{~min}$ at $150{ }^{\circ} \mathrm{C}$ rising to $250{ }^{\circ} \mathrm{C}$ at $8{ }^{\circ} \mathrm{C} \mathrm{min}-1$ and helium as the carrier gas.

Alditol acetates were analysed on a packed column $(0.9 \mathrm{~m} \times 2 \mathrm{~mm}$ i.d.) of $3 \% \mathrm{SP} 2340$ on $100 / 120$ Supercoport with temperature programming from $180^{\circ} \mathrm{C}$ to $240{ }^{\circ} \mathrm{C}$ at $2{ }^{\circ} \mathrm{C} \mathrm{min}-1$ and $\mathrm{N}_{2}\left(40 \mathrm{ml} \mathrm{min}^{-1}\right)$ as the carrier gas.

\section{RESULTS}

\section{Extraction and purity of LPS}

Phenol/water extraction gave yields of purified LPS (weight of LPS from weight of dried cells) of $3-6 \%(w / w)$ from strains $b$ and $f, 0 \cdot 5-1 \%(w / w)$ from strains $d$ and $e$ and $0 \cdot 1 \%$ from strains a and c. PCP extraction, on the other hand, yielded $1-2 \%(\mathrm{w} / \mathrm{w})$ of purified LPS from strains a and $c, 0.5-1 \%(w / w)$ from strains $d$ and $e$ and only $0.1 \%$ from strains $b$ and $f$. All extracts were analysed.

Purified LPSs contained no detectable nucleic acid as assayed by UV spectra and no more than $1 \%(w / w)$ protein. LPSs were also free of capsular polysaccharide as confirmed by the absence of specific capsular components ribitol in LPSs from strains a and $b$, mannosamine in $d$ and $\mathrm{e}$, fructose in $\mathrm{f}$ and glucosamine (other than in lipid $\mathrm{A}$ ) in c.

\section{Chemical analysis}

All six LPSs contained galactose, glucose and heptose. LPSs from strains b, e and f contained similar amounts of these sugars in approximately equimolar ratio, whereas LPSs from strains a, $c$ and $d$ contained less neutral sugar overall and in different molar ratios (Table 1). In particular, LPSs from strains $\mathrm{c}$ and $\mathrm{d}$ had a markedly lower galactose content $(<25 \%$ of that of other strains).

LPSs obtained from strains $b, d$, e and $f$ with PCP were chemically identical to and gave the same SDS-PAGE profiles as the corresponding phenol/water extracts. In contrast, the compositions of the phenol/water and PCP extracts from strain $\mathrm{c}$ were quantitatively different (Table 1). Because of the minute quantity of LPS extracted with phenol/water, this extract was not analysed further.

Paper chromatography revealed the presence of glucosamine in hydrolysates of lipid A from each strain. A small amount of glucosamine [about $90 \mathrm{nmol}\left(\mathrm{mg} \mathrm{LPS}^{-1}\right.$ ] was also detected in the oligosaccharide from strains $b$ and $d$ using either chemical analysis, GC, or paper chromatography. Only a trace of glucosamine $\left[<10 \mathrm{nmol}(\mathrm{mg} \mathrm{LPS})^{-1}\right]$ was found in hydrolysates of the oligosaccharide from strains a, c, e and $f$, where its most likely origin would have been from lipid A. Each mg of LPS contained from 1.5 to $2.6 \mu \mathrm{mol}$ phosphate and paper 
Table 1. Sugar composition of the oligosaccharide from $H$. influenzae LPS

Results are the means of four determinations \pm SD. Each $1 \mathrm{mg}$ LPS also contained from 21 to $34 \mathrm{nmol}$ TBA-reactive material, possibly KDO. Glucose, galactose and glucosamine were all measured manually and by GC. Heptose was quantified by the cysteine/ $\mathrm{H}_{2} \mathrm{SO}_{4}$ assay using D-glucoheptose as the standard. Assays were done on phenol/water extracts except where indicated.

\begin{tabular}{llcccc} 
& \multicolumn{4}{c}{ Composition [nmol (mg LPS) } \\
\cline { 2 - 5 } \multicolumn{1}{c}{ Strain } & Glucose & Galactose & Heptose & Glucosamine & $\begin{array}{c}\text { Total neutral } \\
\text { sugar }\end{array}$ \\
a (PCP extract) & $200 \pm 15$ & $370 \pm 20$ & $400 \pm 50$ & tr & 0.97 \\
b & $470 \pm 20$ & $410 \pm 10$ & $350 \pm 48$ & $90 \pm 10$ & $1 \cdot 23$ \\
c (PCP extract)* & $310 \pm 25$ & $80 \pm 10$ & $200 \pm 60$ & tr & $0 \cdot 59$ \\
c & $140 \pm 20$ & $140 \pm 20$ & $500 \pm 50$ & ND & $0 \cdot 78$ \\
d & $170 \pm 10$ & $80 \pm 10$ & $270 \pm 25$ & $80 \pm 10$ & $0 \cdot 52$ \\
e & $390 \pm 30$ & $380 \pm 14$ & $440 \pm 45$ & tr & $1 \cdot 21$ \\
f & $460 \pm 40$ & $500 \pm 16$ & $300 \pm 50$ & tr & $1 \cdot 26$ \\
& ND, Not determined; tr, less than 10 nmol (mg LPS) & &
\end{tabular}

chromatography revealed the presence of a substantial amount of ethanolamine and ethanolamine phosphate in each LPS. No other amino compounds were detected.

An optimum release of galactose and glucose from LPS was achieved by hydrolysis of LPS with $2 \mathrm{M}-\mathrm{HCl}$ at $100^{\circ} \mathrm{C}$ for $20 \mathrm{~min}$. However, maximum detection of heptose by $\mathrm{GC}$ as its heptitol derivative was only achieved by using stronger acid (e.g. $4 \mathrm{M}-\mathrm{HCl}$ at $100{ }^{\circ} \mathrm{C}$ for $20 \mathrm{~min}$ ). The quantification of heptitol by GC under these conditions gave similar results to the cysteine $/ \mathrm{H}_{2} \mathrm{SO}_{4}$ assay. Therefore, it is suggested that the heptose residues are either extensively phosphorylated, preventing detection by GC, or are involved in extremely acid-stable linkages. A small amount of TBA-reactive material, indistinguishable from authentic KDO by this assay, was present in each LPS.

Lipid A constituted about $50-60 \%(w / w)$ of the LPS from strains b, e and $f$ and about $60-70 \%$ $(w / w)$ of material from strains a, $c$ and $d$. Together with glucosamine and phosphate the lipid $A$ from each strain contained equimolar amounts of the fatty acids 14:0 and 3-OH 14:0. In addition, some LPS samples contained small amounts of fatty acids 16:0 and 16:1. These accounted for no more than $5 \%(\mathrm{w} / \mathrm{w})$ of the total fatty acid content and probably came from traces of phospholipid. Lipid A from strain b was estimated by GC analysis to contain $280 \pm 20 \mathrm{nmol}$ glucosamine and $620 \pm 30 \mathrm{nmol}$ of each fatty acid per mg LPS, giving a molar ratio of glucosamine/14:0/3-OH $14: 0$ of $1: 2 \cdot 2: 2 \cdot 2$. Each value is the mean of three determinations \pm SD.

Hydrolysis of the strain $\mathrm{b}$ LPS with $1 \%(\mathrm{w} / \mathrm{v})$ acetic acid at $100{ }^{\circ} \mathrm{C}$ for $3 \mathrm{~h}$ liberated the oligosaccharide from lipid A. The oligosaccharide resolved into one symmetrical peak after gel permeation chromatography on Sephadex G-50 or G-25. It was just retained on G-50 and eluted close to the exclusion limit of G-25. An $M_{\mathrm{r}}$ in the region of 2000-4000 was estimated but no greater accuracy was attempted by this method. Analysis of the combined carbohydratecontaining fractions revealed the presence of glucose, galactose, heptose, glucosamine and the TBA-reactive component in identical molar ratios to those found by analysis of sugars liberated directly from intact LPS.

\section{$S D S-P A G E$}

The mobility of $H$. influenzae LPS on SDS-PAGE was similar to that of rough LPS from Ra mutants of Salmonella. The mobilities of purified LPSs from strains b, e and $f$ were very similar and were lower than those of strain a, c and d LPSs (Fig. 1). Thus, differences in mobility reflected quantitative differences in sugar composition, i.e. those LPSs with a comparatively low 


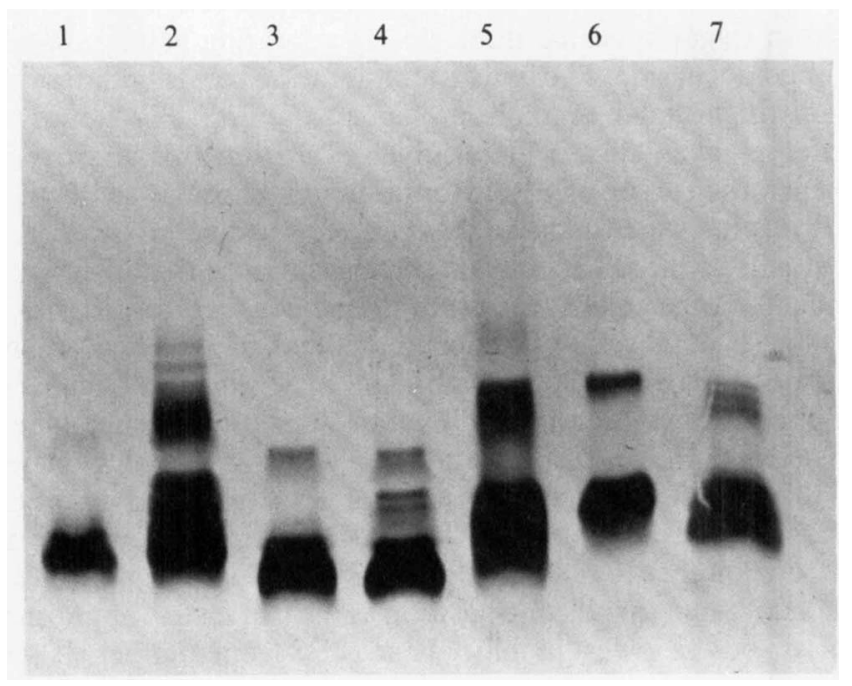

Fig. 1. Analysis by SDS-PAGE of purified LPS from strains of $H$. influenzae of different capsular serotype. Lanes 1-7 show purified LPS ( $5 \mu \mathrm{g}$ per lane) from strains: 1, Morgan (type a); 2, Eagan (type b); 3, ATCC 9007 (type c); 4, ATCC 9008 (type d); 5, ATCC 9009 (type e); 6, ATCC 9010 (type f); 7, Salmonella typhimurium (Ra mutant).

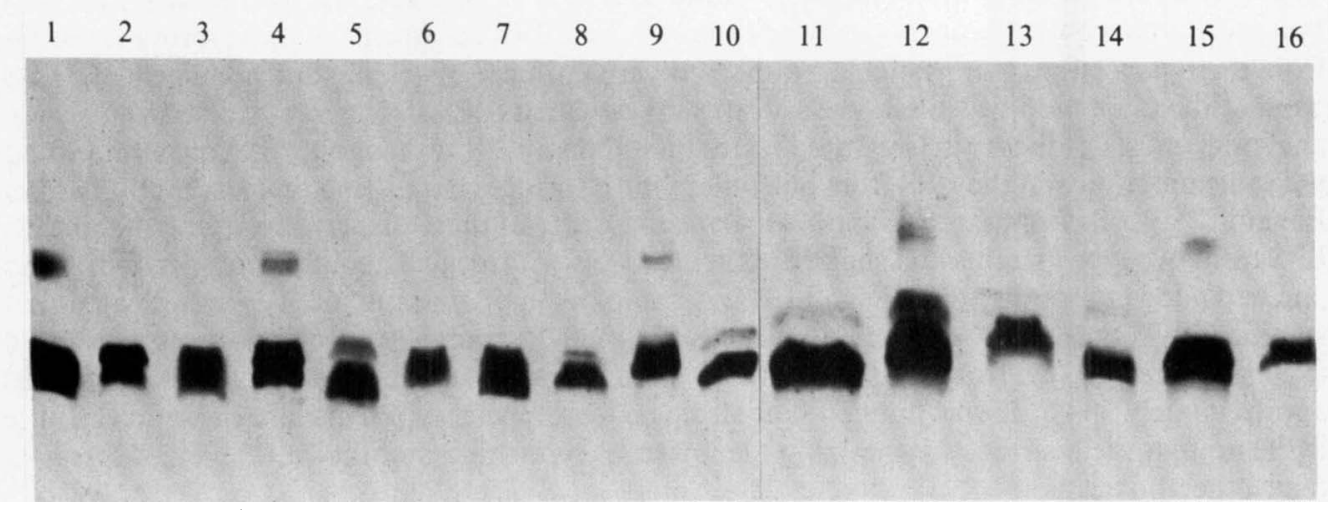

Fig. 2. Analysis of LPS from strains of serotype b. The LPS was isolated by a rapid phenol/water extraction, resolved by SDS-PAGE and visualized by silver staining. Lanes 1-16 show the LPS from strains: 1, TA250; 2, IB4 394; 3, 4F-3334; 4, KA 8; 5, Eagan; 6, B-8917; 7, RM1005; 8, 313; 9, 668; 10 , RSM; 11, H113; 12, Eagan; 13, Jon; 14, IU-4; 15, CS4P; 16, RM 7069.

polysaccharide content (strain a, c and d LPSs) migrated faster than those with a higher polysaccharide content (strain b, e and $f$ LPSs). In general, it is suggested that the differences in mobility of LPS observed between strains of $H$. influenzae are most likely to be due to quantitative differences in either the galactose or glucose content of the LPS, or both.

Although the characteristic banding pattern of a smooth LPS was not seen, one or more relatively high- $M_{\mathrm{r}}$ bands of varying intensity were occasionally observed in both purified LPSs and rapid extracts (e.g. Fig. 1, lanes 2, 5 and 6 and Fig. 2, lanes 1 and 4). These were much more obvious when higher LPS concentrations (i.e. $>5 \mu \mathrm{g}$ per sample well) were used and when conditions were less likely to bring about disaggregation, e.g. by incorporating a lower concentration of SDS in the sample buffer and separating gel. From chemical and immunochemical analysis it appears unlikely that $H$. influenzae LPS possesses any sidechain polysaccharide and it is thought that these bands represent LPS aggregates. 
LPS from strain Eagan revealed three closely migrating bands, suggesting heterogeneity of the size of the oligosaccharide. The two faster migrating bands both stained intensely with silver and became indistinguishable on more prolonged staining. The slower migrating band which stained less intensely was always discernible. LPS from this strain was used as a standard mobility marker in the survey of LPSs from different capsular serotype strains. LPSs from 41 different type $b$ strains were analysed and placed into five groups according to their overall mobility. About half of these LPSs clearly produced more than one band. Such heterogeneity was less clear in the other LPSs but some of the broader bands, although appearing fairly homogeneous, might actually have been composed of two or more closely migrating bands. The highest number of bands observed from any one LPS was four. Comparisons of mobility were made according to the distance migrated by the lowest mobility band. Seventeen type b strains possessed LPSs (group 1 LPS; Fig. 2, lanes 1-4, 6, 7 and 9) which characteristically migrated slightly faster than the lowest mobility band of Eagan LPS. The profiles of the LPSs from another five strains appeared identical to that of Eagan LPS (group 2 LPS; Fig. 2, lanes 5, 8, 10 and 12). LPSs from another four strains (group 3 LPS; Fig. 2, lane 13) revealed one or possibly two bands which migrated to the same position as the two fastest migrating bands of Eagan LPS, but these LPSs lacked the lowest mobility band. LPS from another six strains had very slightly higher mobilities than group 3 LPS (group 4 LPS; Fig. 2, lanes 15 and 16). Another nine strains possessed LPSs with distinctly higher mobilities than Eagan LPS (group 5 LPS; Fig. 2, lanes 11 and 14); of these, three strains are known to be avirulent in the infant rat model (unpublished data).

LPSs from fifteen type a strains, seven type c strains and five type $d$ strains were analysed. These all had high mobilities, similar to group 5, type b LPS. Thus, a high-mobility LPS (low polysaccharide content) appears to be a feature of the LPS from strains of these serotypes. LPSs from the type a strains, in particular, appeared very uniform, revealing one homogeneous LPS band of the same mobility in all type a strains investigated. LPSs from eight type e strains were analysed and six of these also migrated faster than Eagan LPS, although LPSs from strain e had the same mobility and the LPS from one other type e strain had a distinctly lower mobility than Eagan LPS. LPSs from six type $f$ strains were analysed and these displayed varying mobilities: LPS from two type f strains had slightly higher mobilities, three had about the same mobility and one had a lower mobility than Eagan LPS. A comparison of staining intensities indicated that significantly less LPS was extracted by the rapid method from strains of serotypes a, $c$ and $d$ (approximately $10 \mu \mathrm{g}$ from a $10 \mathrm{ml}$ culture) than from serotypes $\mathrm{b}$, e and $\mathrm{f}$ which yielded approximately $30 \mu \mathrm{g}$. It was noticed that strains of serotype $c$, in particular, yielded very little LPS and that the b strains synthesizing the lower $M_{\mathrm{r}}$ type (high mobility) LPS yielded less LPS than other $b$ strains.

The antisera raised against the purified LPSs from Morgan (type a), Eagan (type b), ATCC 9007 (type c) and ATCC 9008 (type d) showed a certain degree of specificity for their homologous antigens in ELISA (Table 2). Antisera against type a, $c$ and d LPSs showed strong homologous reactions. Antiserum against type d LPS cross-reacted to a small extent with type $b$ LPS, but not with any of the other LPSs. Antiserum against type b LPS, in turn, showed greatest cross-reaction with type $d$ LPS, but also cross-reacted with type a, d, e and f LPSs. Antiserum against type c LPS showed a small degree of cross-reaction with type d LPS only. Antiserum against type a LPS cross-reacted to about the same extent with all except type $d$ LPS, which was non-reactive. In contrast, antisera raised against type e and f LPSs were not specific; the antiserum against type e LPS cross-reacted extensively with each LPS and that against type f LPS cross-reacted strongly with type c and e LPSs, to an intermediate extent with type b LPS, but less strongly with type a and d LPSs.

\section{DISCUSSION}

LPSs from all six capsular types of $H$. influenzae were similar in composition. In particular, LPSs from strains $b$, e and $f$ contained similar amounts of the neutral sugars glucose, galactose and heptose; they also had similar electrophoretic mobilities and cross-reacted serologically. In 
Table 2. ELISA study of cross-reactions between LPSs and antisera raised against purified LPSS

The dilutions of antiserum used are shown in parentheses. Each LPS was coated onto the plates at a concentration of $5 \mu \mathrm{g} \mathrm{ml}^{-1}$ in $0.1 \mathrm{M}-\mathrm{Na}_{2} \mathrm{CO}_{3}$ buffer, $\mathrm{pH} \mathrm{9.6}$. Assays were repeated at least four times and the results presented are representative.

\begin{tabular}{|c|c|c|c|c|c|c|c|}
\hline \multirow[b]{2}{*}{$\begin{array}{l}\text { LPS } \\
\text { type }\end{array}$} & \multirow[b]{2}{*}{ Antiserum type } & \multicolumn{6}{|c|}{$A_{492}$} \\
\hline & & $\underset{(1 / 5000)}{a}$ & $\begin{array}{c}\mathrm{b} \\
(1 / 500)\end{array}$ & $\stackrel{c}{c}$ & $\underset{(1 / 1000)}{d}$ & $\begin{array}{c}\mathrm{e} \\
(1 / 100)\end{array}$ & $\underset{(1 / 1000)}{f}$ \\
\hline $\mathbf{a}$ & & $1 \cdot 15$ & $0 \cdot 21$ & 0.07 & $0 \cdot 10$ & 0.95 & $0 \cdot 19$ \\
\hline b & & 0.52 & 0.72 & 0.05 & 0.55 & 0.68 & 0.47 \\
\hline c & & 0.65 & 0.38 & 0.95 & 0.05 & 0.36 & 1.45 \\
\hline d & & 0.12 & 0.56 & 0.45 & 0.95 & 0.55 & 0.35 \\
\hline e & & 0.43 & 0.38 & 0.05 & $0 \cdot 10$ & 0.65 & 0.69 \\
\hline $\mathrm{f}$ & & 0.57 & $0 \cdot 18$ & 0.05 & $0 \cdot 10$ & 0.55 & 0.75 \\
\hline
\end{tabular}

contrast, LPSs from strains a, $c$ and $d$ showed quantitative differences in composition, especially in their galactose content. They had different electrophoretic mobilities and their homologous antisera displayed greater specificity.

Unlike Inzana et al. (1985), who reported the presence of galactosamine in the oligosaccharide of the LPS from $H$. influenzae strain Eagan, we did not detect this sugar in any of the six LPSs analysed during this study. However, we did detect galactosamine in the LPS from the noncapsulated strain of $H$. influenzae, $\mathrm{Rd}^{-}$(data not shown), which is in agreement with the results of an analysis by Parr \& Bryan (1984). Inzana et al. (1985) obtained Eagan LPS from bacterial cultures grown in supplemented BHI broth to late exponential phase, whereas we isolated the LPS from stationary phase cultures. We therefore also carried out an analysis of LPS from strain Eagan grown to late exponential phase (4-5 h growth; approximately $10^{9}$ c.f.u. $\mathrm{ml}^{-1}$ ); culture, extraction and purification methods were all as before. The LPS from exponential phase culture was quantitatively identical to the LPS from stationary phase culture, although the intensity of the lowest mobility band in SDS-PAGE was reduced compared with that of the stationary phase LPS. A similar observation of variation in staining intensities was made by Inzana (1983).

The amount of KDO detectable in $H$. influenzae LPS based on its estimation with TBA has previously been reported to be in the region of $0 \cdot 3 \%(w / w)$ (e.g. Flesher \& Insel, 1978; Parr \& Bryan, 1984), a low value which may be due to the presence of C-4 and C-5 linked substituent groups. Based on an assay using semicarbazide, Inzana et al. (1985) estimated one KDO residue to be present per molecule of $H$. influenzae LPS. Parr \& Bryan (1984) also reported that they could greatly increase the amount of KDO detected with TBA to $3 \%(w / w)$, equivalent to that of a Salmonella smooth LPS, by increasing the strength of acid for hydrolysis of the LPS to $4 \mathbf{M -}$ $\mathrm{HCl}$, presumably because of the removal of substituents. A similar finding was made in this study, although the maximum KDO content was estimated to be only about $1 \%(w / w)$, which is still insufficient to satisfactorily account for one residue of KDO per LPS molecule. This same amount could be detected when hydrolysates of LPS oligosaccharide prepared with $2 \mathrm{M}-\mathrm{HCl}$ were subsequently treated with alkaline phosphatase, suggesting that positions C-4 or C-5 of the KDO are substituted with phosphate. Due to the difficulties of detection of small amounts of substituted KDO with TBA it seems most likely that this value is an underestimate.

The lipid A composition of $H$. influenzae LPS differs from that of enterobacterial LPS in lacking fatty acids $16: 0$ and $12: 0$ and in having a greater proportion of $14: 0$ compared with 3-

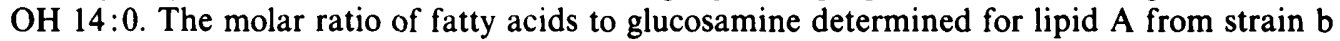
could be accounted for by substitution of a backbone disaccharide of glucosamine with 4 mol each of $3-\mathrm{OH} 14: 0$ and $14: 0$. It is possible that all the $3-\mathrm{OH} 14: 0$ residues are substituted at their hydroxyl groups by $14: 0$.

The lack of specificity shown in ELISA by antisera raised against the purified LPS from strains $b$, e and $f$ is reflected in the similar sugar compositions of the LPSs. The strong crossreaction of type $d$ antiserum with type b LPS and vice versa could be due to the presence of 
glucosamine in the oligosaccharide of both these LPSs, thus providing an epitope not present on type a, c, e or $f$ LPSs.

The antisera against type $c$ and d LPSs, which are both galactose deficient compared with type a, b, e and f LPSs, both show a specific homologous reaction, an observation which suggests that galactose residues in $H$. influenzae LPS could possibly be of particular serological importance. In accordance, recent data (S. E. Zamze, unpublished observations) obtained using LPS-variants and monoclonal antibodies (Kimura \& Hansen, 1986) indicate that the terminal non-reducing end of the oligosaccharide of $H$. influenzae type b LPS is composed of galactose residues which form an immunodominant region.

Little antigenic heterogeneity has been found among LPSs from $H$. influenzae type b strains using either polyclonal antisera or monoclonal antibodies. Van Alphen et al. (1983), for example, using cross-absorbed polyclonal antisera against LPS, found four distinct serological groups within 80 type $b$ isolates examined and, similarly, four antigenic groups could be distinguished by the use of LPS-specific monoclonal antibodies (Gulig \& Hansen, 1985).

The present work suggests that LPSs from serotypes other than $b$ all share some compositional and antigenic characteristics with type b LPS. Despite the rough nature of $H$. influenzae LPS, compositional differences can be detected in the galactose and glucose content of the LPSs which correlate with apparent differences in $M_{\mathrm{r}}$ on SDS-PAGE.

We thank W. Nichols and I. Allan for technical advice and G. Davies for secretarial help. This work was supported by Programme Grant number PG 8325352 from the Medical Research Council and a grant from the E. P. Abraham Trust.

\section{REFERENCES}

Brade, H., Galanos, C. \& Luderitz, O. (1983). Differential determination of the 3-deoxy-D-mannooctulosonic acid residues in lipopolysaccharides of Salmonella minnesota rough mutants. European Journal of Biochemistry 131, 195-200.

Dawson, R. M. C., Elliott, E. C., Elliott, W. H. \& JONES, K. M. (1969). Data for Biochemical Research, 2nd edn. Oxford: Oxford University Press.

Dubois, M., Gilles, K. A., Hamilton, J. K., Rebers, P. A. \& SMITH, F. (1956). Colorimetric method for determination of sugars and related substances. Analytical Chemistry 28, 350-356.

Fensom, A. H. \& MEadow, P. M. (1970). Evidence for two regions in the polysaccharide moiety of the lipopolysaccharide of Pseudomonas aeruginosa 8602. FEBS Letters 9, 81-84.

FLESHER, A. R. \& INSEL, R. A. (1978). Characterization of lipopolysaccharide of Haemophilus influenzae. Journal of Infectious Diseases 138, 719-730.

Galanos, C., Luderitz, O. \& WestPhal, O. (1969). A new method for the extraction of $R$-lipopolysaccharides. European Journal of Biochemistry 9, 245-249.

Gulig, P. A. \& Hansen, E. J. (1985). Coprecipitation of lipopolysaccharide and the 39000-molecularweight major outer-membrane protein of Haemophilus influenzae type b by lipopolysaccharide-directed monoclonal antibody. Infection and Immunity 49, 819-827.

INZANA, T. J. (1983). Electrophoretic heterogeneity and inter-strain variation of the LPS of Haemophilus influenzae. Journal of Infectious Diseases 148, 492499.

InZANA, T. J. \& ANDERSON, P. (1985). Serum factordependent resistance of Haemophilus influenzae type $\mathrm{b}$ to antibody to lipopolysaccharide. Journal of Infectious Diseases 151, 869-877.
InZana, T. J., Seifert, W. E., JR \& William, R. P. (1985). Composition and antigenic activity of the oligosaccharide moiety of Haemophilus influenzae type b lipooligosaccharide. Infection and Immunity 48, 324-330.

KimurA, A. \& Hansen, E. J. (1986). Antigenic and phenotypic variations of Haemophilus influenzae type b LPS and their relationship to virulence. Infection and Immunity 51, 69-79.

LAEMMLI, U. K. (1970). Cleavage of structural proteins during the assembly of the head of bacteriophage T4. Nature, London 227, 680-685.

Moxon, E. R. \& Vaughn, K. A. (1981). The type b capsular polysaccharide as a virulence determinant of Haemophilus influenzae studies using clinical isolates and laboratory transformants. Journal of Infectious Diseases 143, 517-524.

MURPHY, J. \& Riley, J. P. (1962). A modified single solution method for the determination of phosphate in natural waters. Analytica chimica acta 27, 31-36.

NeAL, D. J. \& Wilkinson, S. G. (1982). Lipopolysaccharides from Pseudomonas maltophilia. Structural studies of the side-chain, core and lipid A regions of the lipopolysaccharide from strain NCTC 10257. European Journal of Biochemistry 148, 143-149.

OsBorn, M. J. (1963). Studies on the Gram-negative cell wall. I. Evidence for the role of 2-keto-3deoxyoctonate in the lipopolysaccharide of Salmonella typhimurium. Proceedings of the National Academy of Sciences of the United States of America $\mathbf{5 0}$, 499-506.

PARR, T. R. \& BRYAN, L. E. (1984). Lipopolysaccharide composition of three strains of Haemophilus influenzae. Canadian Journal of Microbiology 30, 1184-1187. 
Pittman, M. (1931). Variation and type specificity in the bacterial species Haemophilus influenzae. Journal of Experimental Medicine 53, 471-492.

Rondle, G. G. M. \& Morgan, W. T. J. (1955). Determination of glucosamine and galactosamine. Biochemical Journal 61, 586-589.

Salkinoja-Salonen, M. \& Boeck, R. (1978). Characterization of lipopolysaccharides isolated from Agrobacterium tumefaciens. Journal of General Microbiology 105, 119-125.

Shands, J. W., Graham, J. A. \& Nath, K. (1967). The morphological structure of isolated bacterial lipopolysaccharide. Journal of Molecular Biology 25, 15-21.

Smith, A. R. W., Zamze, S. E. \& Hignett, R. G. (1985). Composition of lipopolysaccharide from Pseudomonas syringae pv. morsprunorum and its digestion by bacteriophage A7. Journal of General Microbiology 131, 963-974.

ThORNLEY, M. J., LuSHER, M., SCOTT, M. L., COOMBS, R. R. A., Evans, R. T., Thomas, B. J. \& TAYloRRoBinson, D. (1983). Characterization of monoclonal antibody to the group antigen of Chlamydia spp. and its use for antigen detection by reverse passive haemagglutination and indirect immunofluorescence. FEMS Microbiology Letters 17, 45-49.

Tsai, C.-M. \& FrasCh, C. E. (1982). A sensitive silver stain for detecting lipopolysaccharides in polyacrylamide gels. Analytical Biochemistry 119, 115-119.

TURK, D. C. (1982). Clinical importance of Haemophilus influenzae. In Haemophilus influenzae, Epidemi- ology, Immunology and Prevention of Disease, pp. 3-8. Edited by S. H. Sell \& P. F. Wright. New York: Elsevier Biochemical.

Van Alphen, L., Reimens, T., Poolman, J., Hopman, C. \& ZANEN, H. C. (1983). Homogeneity of cell envelope protein subtypes, lipopolysaccharide serotypes, and biotypes among Haemophilus influenzae type $b$ from patients with meningitis in the Netherlands. Journal of Infectious Diseases 148, 75-81.

WESTPHAL, O. \& JANN, K. (1965). Bacterial lipopolysaccharides: extraction with phenol-water and further applications of the procedure. Methods of Carbohydrate Chemistry 5, 83-91.

Zamze, S. E., Smith, A. R. W. \& Hignett, R. C. (1985). Composition of lipopolysaccharide from strains of Pseudomonas syringae pv. morsprunorum of differing host specificity and virulence. Journal of General Microbiology 131, 1941-1950.

Zwahlen, A., Rubin, L. G. \& Moxon, E. R. (1983). Contribution of lipopolysaccharide to Haemophilus influenzae pathogenicity: comparative virulence of genetically related strains (abstract 942). In Program and Abstracts of the 23rd Interscience Conference on Antimicrobial Agents and Chemotherapy. Washington, DC: American Society for Microbiology.

ZWahlen, A., Rubin, L. G., Connelly, C. J., InZana, T. J., Anderson, P. W. \& Moxon, E. R. (1985). Alteration of the cell wall of Haemophilus influenzae type $b$ by transformation with cloned DNA: association with attenuated virulence. Journal of Infectious Diseases 152, 485-492. 